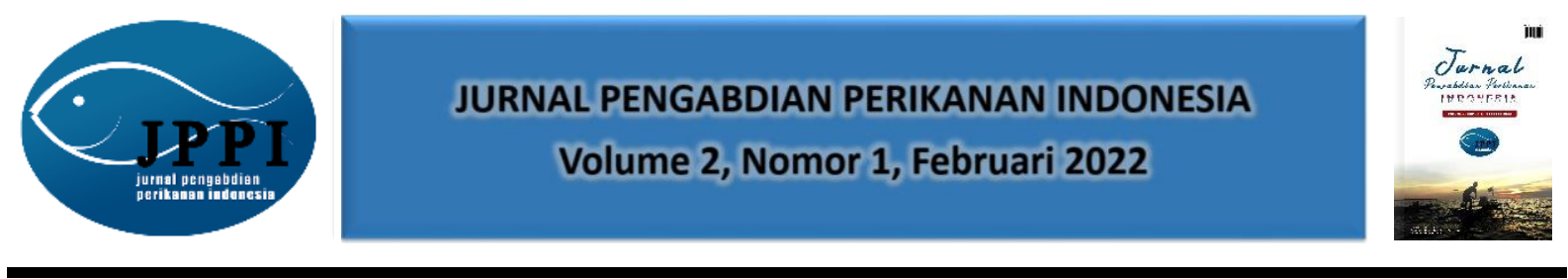

\title{
IMPLEMENTASI TEKNOLOGI BUDIDAYA UDANG VANAMEI DI DESA KURANJI DALANG, LOMBOK BARAT
}

\section{Dewi Nur’aeni Setyowati ${ }^{*}$, Salnida Yuniarti Lumbessy, Dewi Putri Lestari, Fariq Azhar, Lalu Wahyu Wilisetyadi}

Program Studi Budidaya Perairan, Jurusan Perikanan dan Kelautan, Fakultas Pertanian, Universitas Mataram

Jl. Pendidikan 37 Mataram

*Alamat korespondensi : dewins@unram.ac.id

\begin{abstract}
Keyword: Abstrak:
implementa Udang vanamei merupakan salah satu komoditas perikanan yang mempunyai nilai si, budidaya ekonomis tinggi. Desa Kuranji Dalang merupakan salah satu desa yang berada di tepi udang Pantai Kuranji dengan penghasilan masyarakat didapatkan antara lain dari pertanian vanamei, dan penangkapan ikan. Saat gelombang tinggi, maka aktivitas penangkapan ikan Kuranji menjadi terhenti. Hal tersebut dapat berimbas pada berkurangnya pendapatan Dalang masyarakat. Penerapan kegiatan buddiaya udang vanamei di Desa Kuranji Dalang perlu dilakukan. Tujuan dari kegiatan pengabdian adalah untuk mengimplementasikan teknologi Budidaya udang vanamei di masyarakat Desa Kuranji Dalang, Lombok Barat. Manfaat dari kegiatan ini adalah masyarakat dapat menerapkan budidaya udang vanamei dan ke depan dapat menjadi salah satu pendapatan masyarakat Desa Kuranji Dalang. Metode pengabdian adalah dengan memberikan pelatihan dengan demplot budidaya udang vanamei di Desa Kurani Dalang serta pendampingan. Hasil pengabdian menunjukkan bahwa pengetahuan msayarakat terkait budidaya udang vanamei meningkat serta dapat menerapkan budidaya udang vanamei dengan didampingi oleh tim pengabdian. Kesimpulan dari kegiatan ini adalah implementasi teknologi budidaya udang vanamei dapat diterapkan dengan baik di masyarakat Desa Kuranji Dalang.
\end{abstract}

Panduan Sitasi (APPA $7^{\text {th }}$ edition) :

Setyowati, D. N., Lumbessy, S. Y., Lestari, D. P., Azhar, F., \& Wilisetyadi, L. W. (2022). Implementasi Teknologi Budidaya Udang Vanamei Di Desa Kuranji Dalang, Lombok Barat. Jurnal Pengabdian Perikanan Indonesia, 2(1), 7-11. https://doi.org/10.29303/jppi.v2i1.634

\section{PENDAHULUAN}


Desa Kuranji Dalang merupakan salah satu desa di Labuapi,Lombok Barat,Nusa Tenggara Barat. Desa ini berhadapan lagsung dengan Pantai Kuranji. Pendapatan masyarak atDesa Kuranji Dalang diantaranya berasal dari pertanian dan penangkapan ikan (nelayan). Permasalahan pada penangkapan ikan antara lain adalah saat musim gelombang tinggi nelayan tidak bisa melaut dan berdampak pada pendapatan masyarakat.

Udang vanamei merupakan salah satu komoditas perikanan yang memiliki nilai ekonomis baik secara nasional maupun kebutuhan internasional (ekspor). Umumnya budidaya udang vanamei dibudidayakan menggunakan air laut/payau. Desa Kuranji Dalang yang merupakan desa yang dekat dengan pantai potensial untuk penyediaan sarana prasarana utama budidaya udang vanamei yaitu air laut. Kegiatan penyuluhan budidaya udang vanamei skala rumah tangga telah dilakukan oleh Setyowati et al. (2021) di Desa Kuranji Dalang. Oleh karena itu, untuk melanjutkan program tersebut dilakukan impelemntasi budidaya udang vanamei di Desa Kuraji Dalang.

\section{METODE KEGIATAN}

Kegiatan implementasi budidaya udang vanamei di Desa Kurnji Dalang dilakukan dari bulan September-November 2021. Kegiatan tersebut meliputi:

1. Pelatihan,

Mitra di masyarakat Desa Kuranji Dalang dilatih cara melakukan budidaya udang vanamei

2. Persiapan demplot

Persiapan demplot meliputi pemasangan atap, dan persiapan sarana prasarana lain

3. Demplot

Demplot dilakukan selama 2 bulan dengan melakukan buddiaya udang di salah satu masyarakat Desa Kuranji Dalang

4. Pendampingan

Proses pendampingan dilakukan selama masa pemeliharaan udang vanamei

\section{HASIL DAN PEMBAHASAN}

Kegiatan implementasi budidaya udang vanamei dilakukan dengan cara melatih masyarakat Desa Kuranji dalam melakukan budidaya udag vanamei. Pelatihan dilakukan dengan cara partisipatif, diskusi dan tukar pendapat dengan masyarakat terhadap budidaya udang vanamei. Masyarakat diberikan bimbingan teknis budidaya udang vanamei serta berdiskusi terkait sarana prasarana budidaya udang vanamei. Berdasar hasil diskusi tersebut maka masyarakat menawarkan untuk melakukan budidaya udang vanamei di rumah salah satu warga yang halamannya cukup untuk lokasi budidaya udang vanamei dan lokasinya tepat di depan pantai sehingga memudahkan dalam mengambil air laut untuk budidaya udang vanamei. 


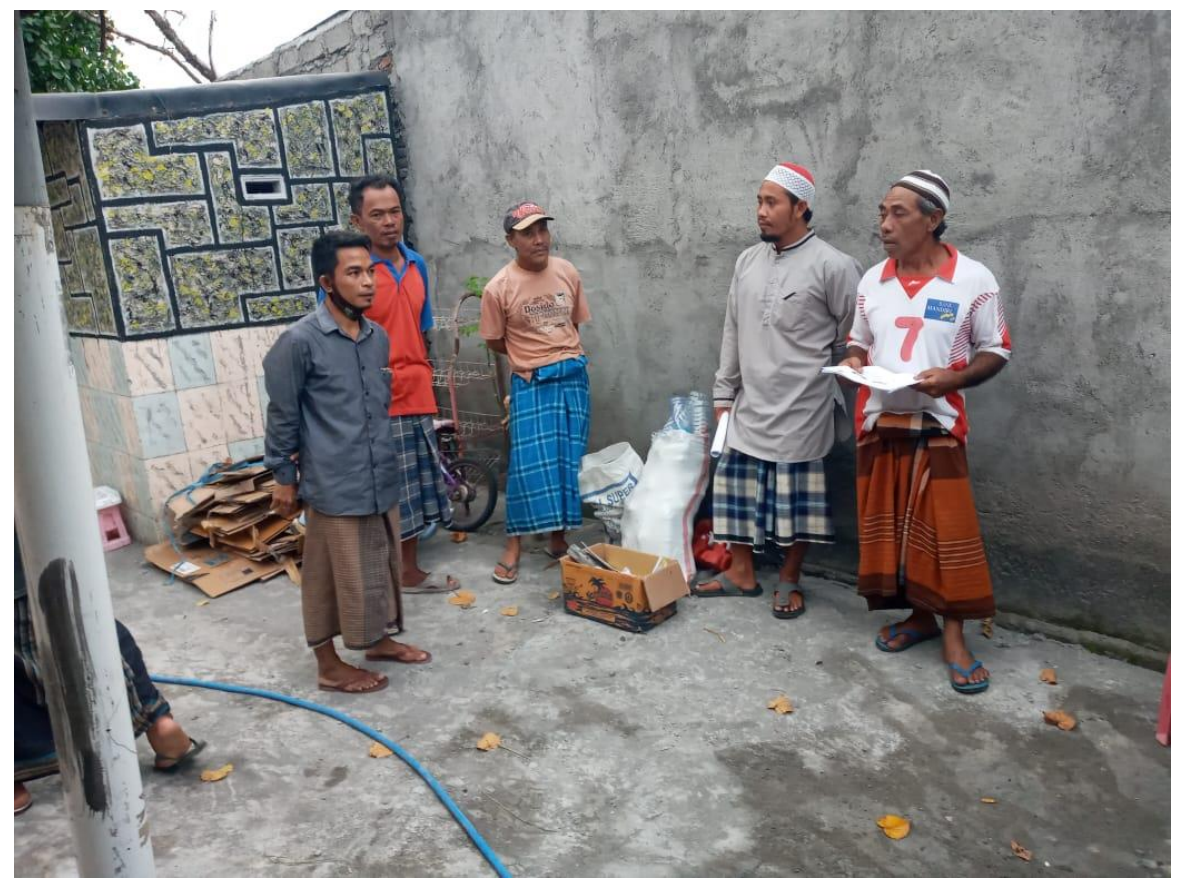

Gambar 1. Peserta pelatihan

Persiapan demplot dilakukan antara lain dengan menyiapkan naungan untuk budidaya udang vanamei. Dengan adanya naungan,maka kualitas air budidaya udang vanamei akan lebih stabil saat turunnya hujan. Curah hujan yang tinggi akan menyebabkan rendahnya kadar garam (salinitas) dan suhu perairan (Ikbal et al.,2019).
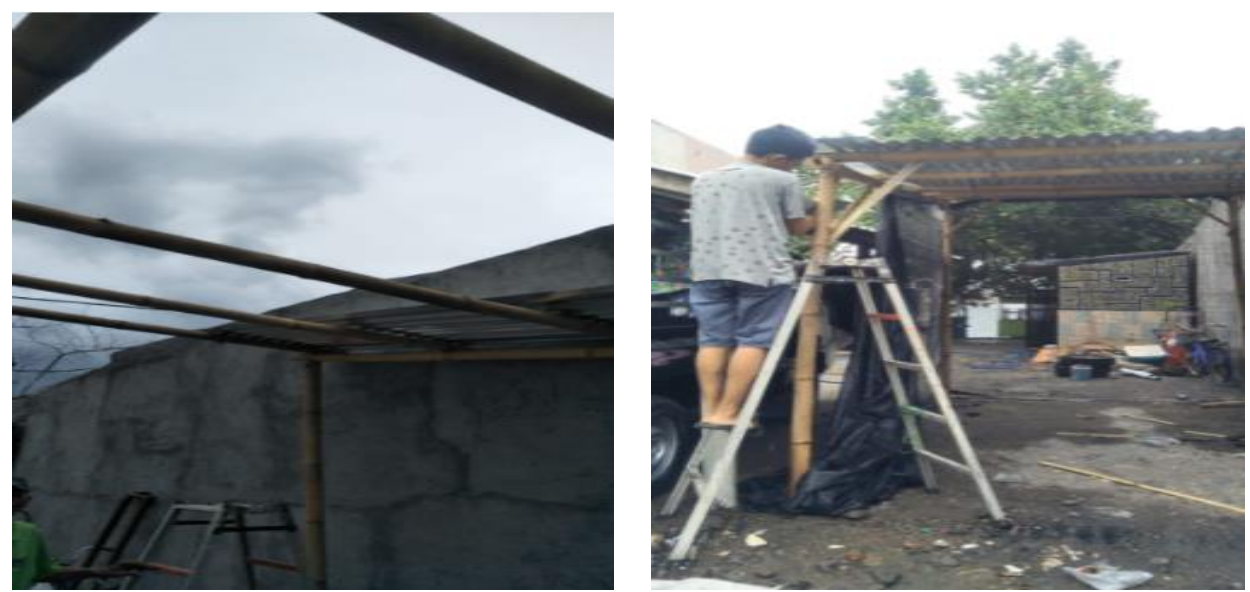

Gambar 2. Pembuatan atap untuk naungan budidaya udang vanamei

Kegiatan demplot dilakukan selama 2 bulan dengan melakukan budidaya udang di salah satu masyarakat Desa Kuranji Dalang. Benur (bibit) udang vanaei diperoleh dari Lombok Utara. Benur setelah dibawa dari Lombok Utara ditebar ke bak pemeliharaan. Pemeliharaan dilakukan selama 2 bulan. Pemeliharaan udang vanamei selama 2 bukan dapat menghasilkan size 80 (80 ekor dalam $1 \mathrm{~kg}$ ) (Setyowati et al.,2021). 


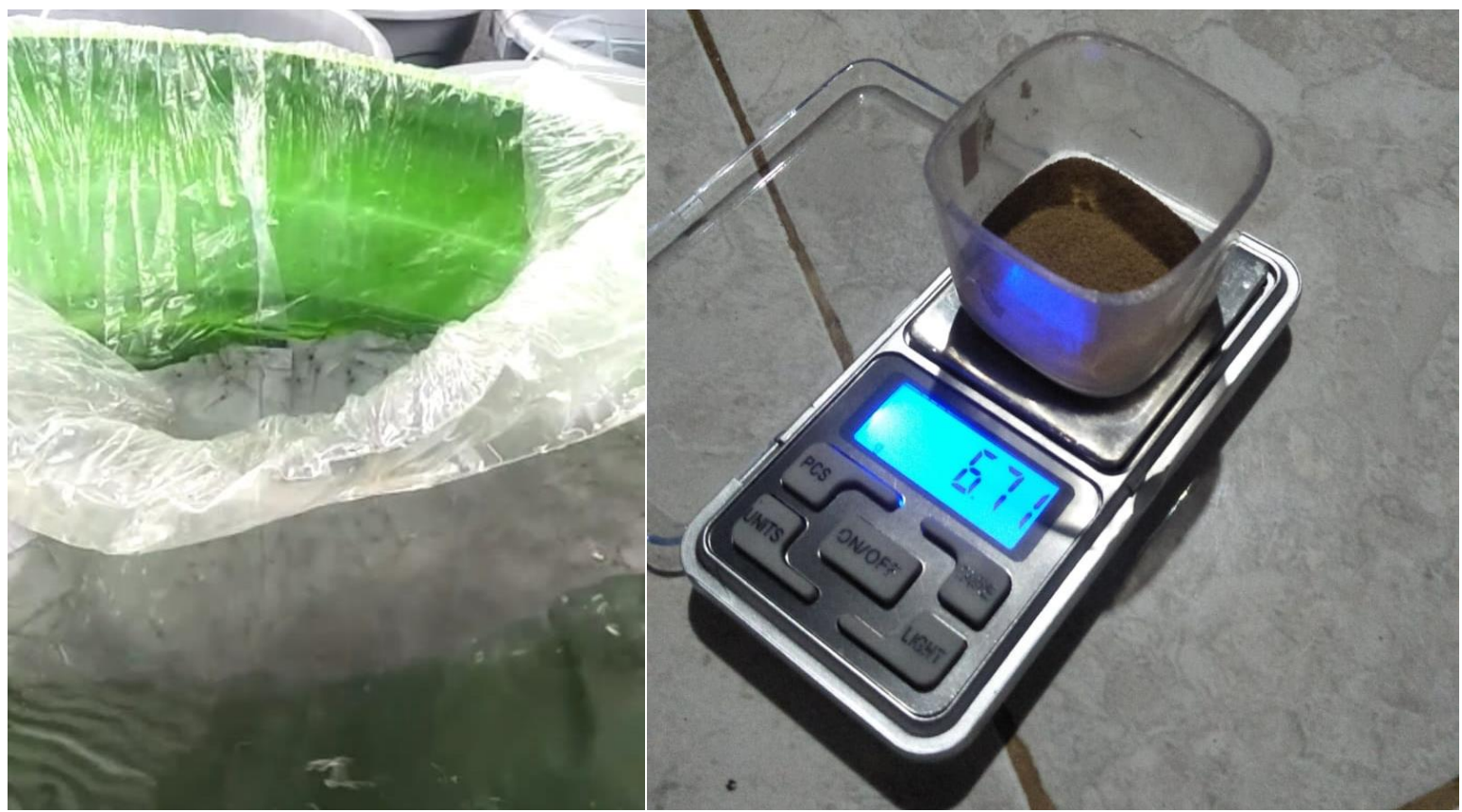

Gambar 3. Penebaran benur (bibit) udang vanamei dan Penimbangan pakan udang vanamei

Selama pemeliharaan, udang vanamei diberikan pakan berupa pelet komersil. Pemberian pelet disesuaikan dengan berat tubuh udang total. Penelitian Safitrah et al. (2020) menggunakan pelet untuk pemeliharaan udang vanamei dari umur PL22. Hasil pemeliharaan di demplot menunjukkan bahwa berat udang mengalami peningkatan selama pemeliharaan (gambar 5).

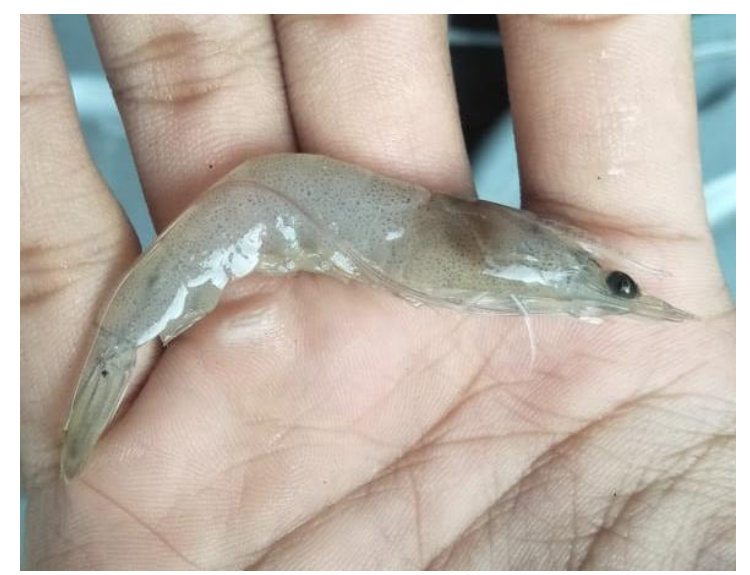

Gambar 4. Udang vanamei pemeliharaan 40 hari

Selama pemeliharaan dilakukan proses pendampingan terhadap mitra. Pendampingan bertujuan agar mitra dapat melakukan proses budidaya udang vanamei dengan baik sehingga menghasilkan pertumbuhan dan kelangsungan hidung udang vanamei yang optimal. 


\section{KESIMPULAN DAN SARAN}

Kesimpulan dari kegaiatan pengabdian adalah implementasi teknologi budidaya udang vanamei dapat diterapkan dengan baik di masyarakat Desa Kuranji Dalang karena menghasilkan pertumbuhan udang vanamei yang baik

Saran untuk selanjutnya adalah penerapan budidaya udang vanamei di Desa Kuranji Dalang secara lebih luas sehingga dapat berimplikasi nyata terhadap peningkatan ekonomi masyarakat Desa Kuranji Dalang

\section{UCAPAN TERIMA KASIH}

Penulis mengucapkan terima kasih kepada Universitas Mataram yang telah memberi dukungan finansial terhadap pengabdian ini melalui dana PNBP.

\section{DAFTAR PUSTAKA}

Ikbal,M., Agussalim, A., Fauziyah. 2019. Evaluasi Status Kesesuaian Lahan Tambak Udang Vaname (Litopenaeus vannamei) menggunakan Sistem Informasi Geografis (SIG) di Tambak Bumi Pratama Mandira Kabupaten Ogan Komering Ilir,Sumatera Selatan. Maspari Journal. 11(2): 6768

Setyowati, D. N.,Lumbessy, S. Y., Lestari,D. P., Azhar, F., Wilisetyadi,L. W., Hermansyah,A. 2021. Penyuluhan Budidaya udang Vaname (Litopenaeus vannamei) Skala Rumah Tangga di Desa Kuranji Dalang,Lombok Barat. Jurnal Pengabdian Magister Pendidikan IPA. 4(4): 180-182

Safitrah, L., Setyowati, D. N., Astriana, B. H. 2020. Efektivitas Ekstrak Kulit Pisang Kepok (Musa balbisiana colla) dalam Pakan Komersial untuk Menurunkan Kanibalisme pada Udang Vaname (Litopenaeus vannamei). Jurnal Kelautan. Vol 13 (1): 36-44 